\title{
LA MÉTRICA DE MINTURNO
}

\author{
ESTEBAN TORRE
}

Resumen: En este trabajo se hace un análisis completo de la teoría métrica de Minturno, sobre la base de dos obras fundamentales del Renacimiento italiano: $D e$ poeta (1559) y L'arte poetica (1564). En la métrica de Minturno, es esencial la concepción del verso -verso intero- como un todo, y no meramente como un compuesto de partes menores, o pies métricos. Algunos autores españoles, como Rengifo y Cascales, siguen en sus tratados una doctrina similar.

Palabras clave: Renacimiento, poética, métrica, ritmo, Minturno, Rengifo, Cascales.

Abstract: A complete analysis of Minturno's metrical theory is done in this paper, on the basis of two fundamental works of the Italian Renaissance: De poeta (1559) and L'arte poetica (1564). In Minturno's metrics, the concept of verse -verso intero- as a whole, and not merely as a compound of minor units, or metrical feet, is essencial. Some Spanish authors, as Rengifo or Cascales, maintain a similar doctrine in their treatises.

Key words: Renaissance, poetics, metrics, rhythm, Minturno, Rengifo, Cascales. 

$\mathrm{E}$

NTRE los tratadistas que conforman la poética o teoría literaria del Renacimiento italiano, destaca la figura de Antonio Sebastiano Minturno (1500-1574), autor de dos obras fundamentales: De poeta (1559), en lengua latina, y L'arte poetica (1564), en lengua italiana. No son ciertamente obras aisladas, sino insertas en un amplio conjunto de trabajos llevados a cabo por distintos autores coetáneos, tales como los comentarios a la Poética de Aristóteles de Francesco Robortello (1516-1567), en latín, o los de Lodovico Castelvetro (1505-1571), en italiano. En la actualidad, se trata desgraciadamente de obras más citadas que leídas, a pesar que algunas de ellas gozan de edición facsímil, como es el caso de L'arte poetica (Wilhelm Fink, Munich, 1971) de Minturno. Tanto ésta como el De poeta son, por otra parte, de fácil acceso a través de la oferta telemática de la casa Google.

La reciente aparición del Arte poética, con traducción española, en cuidada edición bilingüe ${ }^{1}$, hace ahora inexcusable la lectura de esta obra señera por parte de los estudiosos de la poética en general, y en particular de la métrica, a la que se dedican abundantes y enjundiosas páginas en los cuatro libros de que consta el tratado. La profesora María del Carmen Bobes Naves, autora de la encomiable traducción de la obra, nos hace ver en un esclarecedor estudio introductorio cómo nos hallamos ante la primera poética en lengua vulgar, que nos ofrece también por vez primera el esquema de los tres géneros de poesía: épica, escénica y mélica. Sin embargo, y como la misma profesora Bobes Naves se encarga de puntualizar, la obra carece de un esquema general, lo cual propicia las repeticiones y las divagaciones por temas colaterales.

MINTURNO, Antonio Sebastiano: Arte poética Ed. y trad esp. de Ma. Del Carmen Bobes Naves. Madrid: Arco/Libros, 2009. 
De ahí que se haga precisa una lectura sistematizadora, que, en lo que concierne a la métrica, será el objeto del presente trabajo.

El Arte poética consta de cuatro libros, organizados a modo de razonamientos o diálogos que mantiene Minturno con cuatro amigos, que son a la vez poetas y conocedores de la teoría literaria. Le solicitan éstos que explique en lengua vulgar lo que con anterioridad había escrito, en lengua latina, en su obra De poeta ${ }^{2}$. Se divide el De poeta en seis libros, de los que, en realidad, sólo se trata de la métrica escasamente en el libro tercero, a propósito de la versificación utilizada en las partes recitadas y en los coros de las tragedias, y con mayor extensión en el libro sexto, que dedica las páginas 489509 a la composición (compositio), la armonía (concinnitas) y el ritmo (numerus).

En un trabajo sobre la teoría métrica del De poeta, considera el profesor Carlos de Miguel Mora, de la Universidad de Aveiro, que se le da un tratamiento escaso, somero e insuficiente $^{3}$, ya que, de las 134 páginas de uno de sus seis libros -el sexto-, sólo diez están dedicadas a una pequeña exposición de la doctrina métrica. También hace referencia a la deuda contraída por Minturno con el Orator de Cicerón, del que reproduce varios párrafos palabra por palabra. Pero, a decir verdad, no son diez, sino veinte, las páginas que se dedican a la métrica, y además en formato de cuarto mayor. Y, por otra parte, Minturno no oculta nunca la procedencia de sus citas: «lo que dice Cicerón» (quod ait Cicero), «como justamente dice Cicerón» (ut vere ait Cicero).

En cualquier caso, para la historia y la teoría de la métrica, revisten mayor interés las páginas del Arte poética que las de $E l$ poeta, que prácticamente se reduce a una minuciosa

2 Antonii Minturni ad illustrissimum vibonensium ducem Hectorem Pignatellum, de poeta. Venecia: Franciscum Rampazetum, 1559. Sobre esta obra, vid. COLOMBO, Davide: «La struttura del De Poeta di Minturno». Acme: annali della Facoltà di lettere e filosofía dell'Università degli studi di Milano, 2002, Vol. $55, \mathrm{~N}^{\circ} .2$, pp. 187-200.

MIGUEL MORA, Carlos de: «La doctrina métrica en el De poeta de Minturno», en J. Luque Moreno y P. Díaz Díaz (eds.), Estudios de métrica latina. Granada: Universidad, 1999, pp. 617-632. 
relación de los pies métricos -troqueos, espondeos, dáctilos, coriambos, molosos, peanes primeros, antibaquios, doriscos-, aunque también esboza algunas de las ideas que serán desarrolladas más tarde en el Arte poética, como por ejemplo la identificación de las sílabas «agudas» (tónicas) con las «largas», y las «graves» (átonas) con las «breves». Escribe Minturno que los gramáticos «dicen que la sílaba que suena de forma aguda es más larga que la que suena de forma grave» (Syllabam vero, quae acute sonat, longiorem esse aiuntque quam eam quae graviter), y que asimismo es más larga la sílaba «que se marca con una tilde circunfleja» (quae apice circunducto notatur $)^{4}$.

Por lo que respecta al Arte poética, su primer libro ${ }^{5}$ está dedicado a la poesía épica; pero, inicialmente, se hace un estudio general de la poesía, que se define como «imitación de varios tipos de personas, de modos diversos, con palabras, con armonía o con tiempos». El diálogo tiene lugar entre Vespasiano Gonzaga y Antonio Minturno, quien, en la mejor línea aristotélica, pasa revista a la materia, los instrumentos y los modos de la imitación.

Tras esta primera tríada, vienen otras. En la materia, esto es, en las cosas que se imitan, hay que considerar las costumbres, los sentimientos y los hechos de las personas. Éstas pueden ser mejores que los hombres de nuestra época, semejantes a ellos o peores que ellos. Por su parte, los instrumentos usados por el poeta, para hacer imitaciones, son: las palabras, la armonía y los tiempos. Las palabras pueden ir «sueltas», esto es, «sin relaciones entre las sílabas, que con determinado y fijado número hacen los versos», o bien relacionadas «con medida establecida y ordenada con voces ligadas y fijadas, que llamamos versos»».

Tres son también los modos o clases de poesía: épica, escénica y mélica o lírica. Tres son, asimismo, las especies de la épica: en prosa (diálogos y relatos), en verso (versos heroicos, versos bucólicos, elegías, epigramas, himnos, tercera rima,

$\overline{4}$ De poeta, pág. 502.

5 Las citas están tomadas de las páginas 2-5 y 8 de la edición original (Venecia, 1564), y 157-163 y 169 de la traducción española (Madrid, 2009). 
octavas) y mixta de verso y prosa (tal como en la Arcadia de Sannazaro, en el Ameto de Boccaccio o el Amore innamorato del propio Minturno). Y tres son, en fin, las clases de la poesía escénica: trágica, cómica y satírica. Sólo la mélica queda fuera de la tricotomía clasificatoria, al menos en este primer diálogo, ya que en el libro tercero se nos dirá también que tres son sus hacedores: líricos, ditirámbicos y gnómicos.

La imitación, y no el verso, es lo que verdaderamente hace poeta al escritor. En efecto, «la imitación hace poeta al escritor, no el escribir en pies medidos». Los que escribieron en verso de medicina, de música o de filosofía han de llamarse médicos, músicos o filósofos, y no poetas, «pues nada, a no ser el verso, tienen en común con Homero». En todo caso, el verso, vehículo de la poesía, es connatural al hombre, pues hemos nacido para hablar, para el canto, para la medida, para el tiempo. Y, como los versos no se hacen sin tiempo y sin medida, «hemos sido creados para hacer versos». El discurso suave que supone el hablar en verso es distinto del de la prosa. Y, «puesto que hablar en verso se hace con medida y con ritmo y con armonía», no hay nada que llegue a nuestros oídos con más dulzura y alegría. Es cierto que la prosa también está dotada de armonía y de ritmo, pero no «bajo normas», ni «con medida establecida».

Se entiende por armonía una «consonancia de voces diversas y acompasadas», y por ritmo «la medida del movimiento de las sílabas y de las palabras». El movimiento puede ser lento o rápido; y el espacio, largo o breve. Del movimiento veloz, viene el sonido agudo; y del movimiento lento, el grave. La armonía aparece en la consonancia de los versos, que se corresponden entre sí, más claramente que en los simples y desnudos, carentes de consonancia.

El libro segundo ${ }^{6}$ del Arte poética desarrolla, a través de un diálogo o ragionamento entre Angelo Costanzo y Minturno, la cuestión de la poesía escénica, que se define como imitación de cosas «de cierta grandeza», lo cual se realiza «no simplemente narrando, sino introduciendo personas en

${ }^{6}$ Las citas están tomadas de las páginas 65-70, 107-109 y 160 del original (284293, 367-371 y 473 de la traducción). 
acción y diálogo, con discurso suave y deleitable; y con canto, y baile». De estos tres elementos - discurso, canto y bailepodrá estar presente sólo uno de ellos, o dos, o los tres conjuntamente. Y es que «el placer y suavidad del habla no sólo procede del sonido, y de los tiempos de las palabras bajo las leyes de las sílabas, y de los pies, sino también del canto».

La materia escénica puede ser de tres clases: grave (de personas elevadas e ilustres), común (de labradores, asalariados y comerciantes) y baja (de personas humildes y risibles). En correspondencia con estas tres clases de materia escénica, existirán tres formas de representación teatral: la tragedia, la comedia y la sátira. Por otra parte, según el modo de imitar, el poeta lírico (que «narra simplemente y sin ocultar su propia persona») se distingue del poeta épico (que «la oculta o la mantiene, en parte narrando o en parte introduciendo a otros que dialoguen»).

En el terreno de la comedia, defiende Angelo Costanzo el uso del «discurso libre y suelto que llamamos prosa», en el cual «se pueden poner los dichos y los hechos más cómodamente», porque no debe caber duda de que «hablar libremente y sin la atadura de las sílabas y de los pies no sea más cómodo y más adecuado para expresar nuestros pensamientos», teniendo además en cuenta que «la poesía no está en el verso más que en la prosa». Por otra parte, las cosas comunes y bajas que se tratan en la comedias exigen un lenguaje que esté «más cerca de la prosa que del verso». Aduce Minturno que los antiguos, cuyo juicio «es mejor y más digno», jamás llevaron la prosa al teatro, ni se representó nada que no hubiese sido escrito en verso. Ahora bien, es lícito utilizar versos sueltos, desnudos y carentes de rima (versi ignudi, e senza consonance: $i$ quali sciolti chiamarono), y también el ritmo dactílico que empleó Sannazaro en sus pastorales, fiel trasunto de los dáctilos latinos, que se llaman en lengua toscana sdruccioli (esdrújulos, "resbaladizos"), que corren y se deslizan como si resbalasen (come se sdrucciolassero).

En cuanto a la medida del verso toscano, dos son las formas fundamentales: los heptasílabos y los endecasílabos. Los primeros son considerados como quebrados o rotos (rotti), 
y los segundos como enteros y perfectos (interi e perfetti). Pero también puede haber versos quebrados de cinco sílabas, como en una canción de Dante:

Poscia ch' Amor del tutto m' hà lasciato,

Non per mio grato;

Che stato non havea tanto gioioso.

Un pentasílabo se inserta aquí entre dos endecasílabos. Pero existe rima interna del segundo endecasílabo con el pentasílabo:

Non per mio grato,

Che stato.

El segmento «Che stato» puede ser considerado como un quebrado de tres sílabas. En realidad, como apunta Minturno, «del verso de once sílabas podemos hacer versos de tres sílabas, de cinco y de siete». Y también de cuatro, de seis y de ocho. Se pone como ejemplo el verso «L'aspetto Sacro de la terra vostra», de Petrarca, que se puede segmentar de varios modos:

\section{L'aspetto}

Sacro de la terra vostra

L'aspetto Sacro

De la terra vostra.

L'aspetto Sacro de la

Terra vostra.

El endecasílabo ha dado origen, como vemos, a versos de tres, ocho, cinco, seis, siete y cuatro sílabas. No le pasó a Minturno desapercibido el hecho de que también habría que incluir en esta serie el verso de nueve sílabas:

L'aspetto Sacro de la terra

En cualquier caso, se considera que los versos cortos más usados son los de tres, cinco y siete sílabas, que, en verdad, son los que mejor se combinan con el endecasílabo, verso 
central de la poesía toscana. Estos versos son más blandos y más gráciles (pîu molli e piû vaghi) que los de cuatro, seis, ocho y doce sílabas, que resultan más duros y ásperos (pîิ duri e aspri). Los primeros serían más aptos para la canción, y los segundos para los diálogos escénicos. El verso de doce sílabas, que «procedería de añadir una sílaba al verso entero y perfecto», es poco usado por los poetas toscanos; pero sí por el español Juan de Mena en la composición que se llama de arte mayor. Advierte Minturno que «crece una sílaba el esdrújulo, y falta una sílaba en aquel que lleva el acento en la última». En consecuencia, en el esdrújulo «dos sílabas valen por una», y en el agudo la última sílaba «vale por dos».

Se cuestiona en este diálogo en qué versos debe escribirse la poesía escénica. Si se tratara de la literatura griega o latina, la respuesta no tendría dificultad alguna, porque tanto en latín como en griego, y especialmente en griego, existen poetas excelentes, que nos podrían servir de guía. Pero, en la lengua toscana, «apenas hace cuarenta años que los nuestros han empezado a escribir poemas escénicos», y no todos siguen los mismos criterios. En todo caso, se proponen algunas reglas. Para los prólogos, que los griegos y latinos hicieron en versos yámbicos, se aconsejan los endecasílabos; para los episodios, los versos de siete u ocho sílabas, y a veces de tres o de cinco, «tejiéndolos según requiera la calidad del hábito o del acto representado», es decir, «en materia muy seria, o donde se narra, se hará uso de versos de once; en materia grave, podéis intercalar los de siete, y a veces el de ocho». Los versos más cortos, de tres o cinco sílabas, se reservan para «el habla presidida por el dolor o el llanto». Por lo demás, «en todos los episodios, en los que hubiere variedad de materia y de habla, usaréis variedad de versos, cambiando según juzguéis que lo requiera el caso»».

Se advierte que todas las estancias han de ser como la primera, excepto la última, que recibe en toscano el nombre de commiato, esto es, "despedida", y equivale al epodo de los griegos. Tanto en el prólogo como en los episodios, se emplearán versos desnudos (versi ignudi), libres de las ataduras de las consonancias (liberi de' legami di consonanze). 
La razón es que éstas no son precisas en la narración y el diálogo. Por lo que respecta a los pies métricos, se considera que los toscanos pueden hacer versos del mismo modo que los hicieron los griegos y los latinos. Así, a los anapestos se asimilan los esdrújulos y, por extensión, todos los versos constituidos por palabras de muchas sílabas, donde los acentos son escasos y espaciados.

Más adelante, sin embargo, distingue entre dáctilos y anapestos. Los primeros son conjuntos de tres sílabas, de las cuales la primera es larga (tónica) y las otras dos breves (átonas), tales como scriuere, candido, pessimo, cuor mio. Los segundos constan de dos sílabas breves y una final larga, como $v a$ lidi. Si las tres sílabas son breves, el pie recibe el nombre de coreo, como ocurre, según Minturno, en la palabra varia. Por su parte, son yambos todas aquellas palabras de dos sílabas derivadas de voces griegas o latinas que no tienen larga la sílaba primera. Son asimismo yambos las palabras de dos sílabas que no lleven consonante entre ellas, como io, suo, lui, o no más de una consonante, siendo breve la primera sílaba, como amo, fede, rosa.

Cuando las dos sílabas son largas, el pie recibe el nombre de espondeo, bien entendido que las sílabas pueden ser largas porque en latín, de donde proceden, sean largas (por naturaleza), como dono, caro; o porque la vocal vaya seguida de dos consonantes (por posición), como ocurre en la primera sílaba de las palabras fronda y canto. Advierte Minturno, identificando una vez más las sílabas tónicas con las largas, que, en la lengua toscana, la penúltima sílaba de toda palabra llana ha de ser considerada siempre como larga: ardeva, signore, sedere. Si el pie bisilábico lleva larga la sílaba primera y breve la segunda, como legge, finge, vista, recibe el nombre de troqueo. Sería el pie más frecuente de la lengua toscana.

Hacia el final del diálogo, Angelo Costanzo le pide a Minturno que, ya que considera que la comedia no debe escribirse en prosa, sino en verso, especifique cuándo y cómo se debe emplear el metro. Responde Minturno que ya había hablado de ello con anterioridad, pero que, por hacer un breve recordatorio, ha de precisar que «todos los modos que siguieron 
los antiguos se reducen a tres, cuyos nombres son yambos, anapestos y troqueos». Constan de ocho o cuatro pies, y raras veces de dos. Para los prólogos, se utilizaban los senarios, que son yambos de seis pies; y para los diálogos de los actores, los versos cuadrados ${ }^{7}$, que son anapestos o troqueos de ocho pies. Entre los cuadrados, se ponían a veces los dímetros, que son de cuatro pies, y alguna vez los monometros, que son de dos. Pero, en la lengua toscana, en vez de senarios, se escriben versos de once sílabas; en vez de cuadrados, los versos de doce; en lugar de los dímetros, los versos de ocho o siete sílabas; $y$, en vez de monometros, los versos de tres o cuatro sílabas, o de cinco, «según pidiese la materia de que se hablase»».

El libro tercero ${ }^{8}$, o tercer diálogo de la Poética toscana, es el que mayor extensión dedica al estudio del verso, la rima y las distintas estrofas y composiciones. El diálogo tiene esta vez lugar entre Bernardino Rota y Minturno, y se ocupa de la poesía mélica, cuyo origen no sería otro sino una acción de gracias al Dios todopoderoso. En efecto, las criaturas «a Dios, su padre y señor, le dieron las gracias, y lo celebraron haciéndole cantos con alabanzas y con concertada medida de los tiempos»». Apolo, príncipe de la poesía, habría inventado la lira, para poner música al poema mélico; de ahí que podamos considerar a los liricos como a los primeros poetas de la historia. «Melos, voz de la que deriva el nombre de mélica, no significa otra cosa que canto, el cual, si se canta con la lira, se llama lírico». Los cantores de la poesía mélica se clasifican de acuerdo con la siguiente tríada: líricos, ditirámbicos y gnómicos.

También son tres las partes de la canción según el modelo seguido por Píndaro: vuelta, revuelta y estancia. Pero, en las canciones toscanas, «se llaman estancias las que en las pindáricas se llaman vueltas». La canción se define como «una composición hecha de palabras con armonía, bajo cierto

$\overline{7}$ Sobre el verso cuadrado, vid. LUQUE MORENO, Jesús: Versus quadratus. Crónica de un verso milenario. Granada: Universidad, 2009. Y reseña de esta obra en la Crítica de Libros del presente número de Rhythmica.

8 Las citas están tomadas de las páginas 167-169, 178 y 185-281 del original (496-499, 517 y 531-723 de la traducción). 
número, y bajo cierta medida, tejidas y ordenadas para el canto». Es consciente Minturno - por boca de Bernardino Rota-de la insuficiencia de esta definición, que podría aplicarse a «todo lo que en verso se compone de forma ordenada», y especifica que se trata de «una composición magnífica y espléndida, y dividida en partes dirigidas a un sentimiento ${ }^{9}$. Por su parte, la instancia es una «composición de versos de sílabas limitadas bajo cierto canto y bajo cierto orden». A su vez, el canto es «armonía de los versos compuestos según cierto número».

Los versos que se utilizan en la canción son fundamentalmente el endecasílabo y el heptasílabo. Los versos de cinco sílabas aparecen con menor frecuencia, y menos aún los de tres. El verso de nueve sílabas se abandonó pronto, «porque era poco apreciado y producía aburrimiento, pues comprendía tres veces el trisílabo». En general, los versos de sílabas impares son los mejores, pues «los que tienen sílabas pares son muy duros y pocas veces se usan». Llega a decir Minturno que los versos de sílabas pares son duros, porque «retienen la naturaleza de los propios números», $\mathrm{y}$, en relación con los de sílabas impares, «son como la materia respecto a la forma». Con esta invocación a la doctrina hilemórfica de Aristóteles, queda la cuestión plenamente justificada.

Las estancias pueden ser continuadas o divididas. Estas últimas pueden ser, a su vez, simples y compuestas. Las simples constan de fronte y sirima; y las compuestas, de pies y versos. La cosa se complica aún más, puesto que tanto la fronte como la sirima pueden ser simples o compuestas. Además, «si la fronte es simple, conviene que la sirima sea compuesta». A partir de aquí, nos sumerge Minturno en un piélago interminable de frontes simples y compuestas, sirimas simples y dobles, partes, números, sílabas, versos, pareados, tercetos, cuartetos, estancias, vueltas y revueltas.

$\overline{9}$ Estas palabras, «composición magnífica y espléndida», en verdad poco definitorias, llamaron sin embargo la atención de Francisco Cascales, que traduce en sus Tablas poéticas (1617) el texto original: «composición magnífica y espléndida, dividida en partes a sólo un pensamiento endereçadas» (composizione magnifica e splendida, e divisa in parti ad un sentimento indrizzate). Vid. Cascales, Francisco: Tablas poéticas, ed. de Benito Brancaforte. Madrid: EspasaCalpe, 1975, p.237. 
Enloscuartetos, lasrimaspuedensercruzadas, «porderecho» (per diritto), abab, o abrazadas, «por oblicuo» (per obliquo), $a b b a$. Los tercetos pueden relacionarse, asimismo, por la rima de diversos modos. Pone Minturno varios ejemplos, que se atienen a los siguientes esquemas: $a b c a b c, a b c c b a, a b c b a c$, $a b c a c b, a b c b c a, a b c c a b$. Se advierte que «hay otros modos de consonancia en los tercetos». En efecto, sólo se han consignado las seis permutaciones posibles con los elementos $a$, $b$ y $c$ del segundo terceto, ya que el primero permanece inalterable. En todos los casos, los versos que se usan en la canción constan de once sílabas «en el estilo heroico, es decir, cuando narramos», o cuando la materia es "grave e ilustre»; por el contrario, se utilizan los versos de siete sílabas «cuando el estilo es cómico, o la materia ligera y suave».

Atención especial se le presta a la sextina, que se compone de seis estancias o estrofas, de seis versos cada una de ellas. "La primera estancia es abcdef, la segunda faebdc», y así sucesivamente, siempre con las mismas voces finales, de manera que el primer verso termina con la misma palabra que el último de la estrofa anterior, el segundo con la del primero, etc. Se añade al final la sezzaia, o contera, «de tres versos enteros», en los que se repiten las seis palabras finales, «a dos por verso». Estas seis palabras finales han de ser «bellas, vagas, elegantes, redondas, sonoras; más bien nombres que verbos; y sustantivos más que adjetivos, y de dos sílabas».

Se podría aumentar el número de las estrofas, «pero hasta ahora no se encuentra más de una vez repetido», y esto por dos motivos: «por lo fatigoso de la composición» y «por evitar el fastidio que el repetir demasiado las mismas voces supondría». Si Minturno hubiera tenido la mente matemática de un Juan Caramuel (1606-1682), las posibilidades combinatorias habrían aumentado de una manera considerable. En efecto, Caramuel, con los seis versos de la sextina, obtuvo en su Rhythmica (1665) nada menos que 720 permutaciones (6!, esto es, factorial de 6) frente a las seis estrofas de la sextina tradicional ${ }^{10}$.

${ }_{10}$ Vid. CARAMUEL, Juan: Rítmica. Ed. de I. Paraíso y trad. de A. Carrera. Valla- 
El soneto es también objeto de particular estudio.«¿Qué es un soneto? Composición grave y elegante con palabras, con armonía de rimas y con medida de sílabas tejidas bajo cierto número de versos y limitada bajo cierto orden». Se diferencia del epigrama, que es una parte de la poesía épica, mientras que el soneto corresponde a la poesía mélica. Soneto es palabra que remite al sonido, como la canción al canto. «Y no porque la voz sea diminutiva denota bajeza alguna del estilo, sino más bien elegancia y belleza». En el soneto no cabe la imperfección o la mediocridad: sin elegancia y sin belleza «esta composición es especialmente nula o vale poco». En el soneto, «las palabras son elegidas y ordenadas de un modo bello y elegante», y son portadoras de «un dulce sentimiento», o bien están compuestas «de un modo grave y agudo». El soneto tiene un número determinado de versos y un final previsto, «que no se puede traspasar», frente al epigrama, que no requiere un número preciso de versos, pues a veces no son más de dos o cuatro.

Como quiera que la definición propuesta para el soneto es muy semejante a la de la canción, y la materia de ambas composiciones «es a veces grave e ilustre», conviene precisar que el soneto «no la dilata», como hace la canción, que «se puede enriquecer y engrandecer con prerrogativas de variadas digresiones», sino que viste esa materia «de todas aquellas riquezas que por sí misma en su pequeño cuerpo puede recibir» y «no añade cosas ajenas para adornarla». Por otra parte, mientras que en la canción hay un número indeterminado de estancias, «en el soneto no puede haber ni más ni menos de catorce versos». Ésta es, al menos, «la forma de los sonetos que está en uso».

Al igual que la canción, el soneto consta de dos partes: fronte y sirima. La fronte está formada por dos cuartetos, y la sirima por dos tercetos. Como vemos, cada una de estas partes se divide, a su vez, en dos: vuelta y revuelta, «semejantes

dolid: Universidad, 2007. Y PARAÍSO, Isabel: «La sextina y su teorización en Juan Caramuel», en A. Álvarez y otros (eds.), Lengua viva. Estudios ofrecidos a César Hernández Alonso. Valladolid: Universidad y Diputación, 2008, pp. 1163-1181. 
e iguales en el número y en la medida de los versos, con el concento de las rimas». Las rimas de los cuartetos pueden ordenarse «o por oblicuo: $a b b a$, o por derecho: $a b a b »$. Si el primer cuarteto se ordena por derecho, el segundo se podrá ordenar de cuatro modos: $a b a b, b a b a, b a a b, a b b a$. Y si el primer cuarteto se ordena por oblicuo, el segundo «se puede variar de otro tantos modos; de ellos, el primero es $a b b a, \mathrm{y}$ es el más usado; el segundo, baab; el tercero, baba; el cuarto, $a b a b$. Queda, así pues, establecido que el esquema más frecuente de los cuartetos es abba abba. Pero pueden darse además otras muchas disposiciones, entre las que se consignan abbb baaa, aaaa bbbb, abab bbaa, ababaabb.

En lo que concierne a los tercetos, las rimas pueden ser dos, o tres, ordenadas por derecho o por oblicuo. Con dos rimas, se proponen los siguientes esquemas: $a b a b a b, a b a a b a$, $a a b b b a, a b b a b b, a b a$ abb, abb aba, abb bab. Con tres rimas: $a b c a b c$ («el primero y el más general de los modos», que es el que aparece en los sonetos de Petrarca), abc bac, abc cba, $a b c b c a, a b b a c c, a b c c a b, a b c a c b, a b a c b c, a b a b c c, a a b$ $c b c$. Puesto que «elegir la variedad es propio de la mélica», y ya que no es posible alterar el número de los versos, es en las rimas donde reside «esta libertad de poder variarlas».

Las rimas de los tercetos han de ser diferentes de las de los cuartetos. En efecto, «esta diferencia es muy usada» y es la que se da en el Cancionero de Petrarca. En cuanto al número de sílabas del verso del que se hace el soneto, es «de once, y de ningún otro verso desde el tiempo de Petrarca». Existen otros muchos tipos de soneto, pero «los que no tienen suficiente elegancia o vaguedad se han ido abandonando del todo».

Enumera Minturno los sonetos simples, comunes y dobles, con cola, continuados, con vuelta, encadenados, repetidos, retrógrados, mudos, esdrújulos, mixtos y de varias lenguas. Son simples cuando todos sus versos son de once o de siete sílabas; comunes, cuando hacen uso de ambas formas de verso; y dobles, cuando intercalan dos heptasílabos en cada uno de los cuartetos endecasilábicos, y un heptasílabo en cada uno de los tercetos. Los cuartetos se convierten así en sextetos, y los tercetos en cuartetos. También se pueden intercalar dos 
heptasílabos en los cuartetos, que se convierten en quintetos.

En los sonetos con cola o caudati, se ponen dos versitos de cuatro o cinco sílabas después de cada dos endecasílabos en ambos cuartetos, y uno más después de cada terceto. Estos pequeños versos riman entre sí, pero no con los endecasílabos. En los sonetos continuados, los tercetos tienen las mismas rimas que los cuartetos. En los sonetos con vuelta, se añade al final un verso que rima con el último; o dos, que riman entre sí; o tres, de los cuales el primero es de siete sílabas y rima con el último verso del soneto propiamente dicho, y los dos siguientes constan de once sílabas y riman entre sí. Como puede observarse, éste es el modelo, llamado con estrambote, que habría de seguir el famoso soneto de Cervantes dedicado al túmulo de Felipe II.

En los sonetos encadenados, el comienzo de cada verso rima con el final del verso precedente. En los repetidos, es la última palabra de cada verso la que se repite al comienzo del siguiente. En los retrógrados, se puede hacer una lectura coherente de derecha a izquierda, o de izquierda a derecha. Los llamados mudos (muti) terminan en palabra aguda, mientras que los esdrújulos (sdruccioli) terminan en palabra esdrújula. Otros son mixtos, misti, de ambas clases de versos. Finalmente, existen sonetos compuestos en dos o tres lenguas.

Varias páginas ocupa el estudio de la balada y su represa. Por balada se entiende «una composición vaga, agradable, con palabras tejidas y ordenadas, apta para el canto y el baile, y dividida en partes dirigidas a un sentimiento deleitoso, sujeta a cierto canto y bajo cierto orden». Tras esta definición profusa, difusa y redundante - palabras ordenadas con cierto orden, composición apta para el canto y sujeta a cierto canto-se especifica que la materia de la que trata es el amor. No conoce Minturno «ninguna que trate de otra cosa», y se canta «en el baile, el cual que no es de hombres graves, sino de jóvenes alegres y de graciosas y bellas damas».

Consta la balada de tres partes: represa, mudanza y vuelta. La represa (ripresa) es, como su nombre toscano indica, continuación o repetición, «porque, al final de ella, los que cantan vuelven a cantar»; la mudanza (mutatione) se llama 
así «porque en ella cambia el canto»; y la vuelta (volta), «porque vuelve el canto de la represa, a la cual en el número de versos y en la medida de las sílabas es semejante e igual».

La represa puede estar formada por un pareado, por un terceto, por un cuarteto, por un quinteto o por un sexteto. Los versos pueden ser todos de once sílabas, o todos de siete, o de una y otra clase. Generalmente, el pareado es de versos «enteros», de once sílabas. La mudanza consta de dos partes, y raras veces de tres. Podrá ser de dos pareados, de dos tercetos o de dos cuartetos; pero también de dos quintetos, o de dos tercetos. En cualquier caso, «tantos y cuáles versos tiene la primera parte, otros tantos y tales conviene que tenga la segunda», guardándose siempre la correspondencia de las rimas. Por su parte, la vuelta «se compondrá de tales y cuantos versos esté compuesta la represa», y sus rimas se dispondrán de modo que el primer verso de la vuelta se corresponda o bien con el último de la mudanza, tal como ocurre en todas las baladas de Petrarca, o con algún otro elemento de la misma.

Se consideran baladas pequeñas las que tienen represa de dos versos, medianas las de tres, y grandes las de cuatro, cinco o seis. Por otra parte, pueden ser simples y desnudas (semplici e ignude), o vestidas (vestite), llamadas también replicadas (riplicate) y empujadas (spingate). Éstas no tienen más que una represa; pero, «si la materia lo requiere, tienen dos o más mudanzas y vueltas con el mismo orden, que después de la mudanza sigue la vuelta».

Definición análoga a la de la balada recibe el madrigal, que se considera como «una vaga composición de palabras, con armonía de rimas y con medida de sílabas, organizadas bajo cierto canto y bajo cierto orden». Se desarrolla «en torno a temas rústicos, de donde toma el nombre», pues procede de mandre (rebaños), de donde viene mandriale (pastor), que más tarde derivó a madrigale (madrigal).

La medida de los versos del madrigal es siempre de once sílabas, ya que «mirando los Cancioneros de los antiguos, no encontraréis en el madrigal versos quebrados». El número de los versos oscila entre ocho y once. El madrigal de ocho versos está compuesto por dos tercetos y un pareado, de 
acuerdo con los siguientes esquemas: $a b c a b c d d, a b a b c b c c$, $a b b$ baa $c c, a b b c d d e e, a b a b a b c c$. El de nueve versos consta de tres tercetos: $a b b a c c c d d$, aba $b a b b c c, a b c, a b c, c d d, a b b$ bac $c d d$. El de diez versos se compone de dos tercetos y un cuarteto: $a b a c b c$ dede; o de tres tercetos y un verso de vuelta: $a b a b b c d d c c$, aba $b c b c d e$ e. Por último, el madrigal de once versos consta de tres tercetos y un pareado: $a b b c d d$ eff $g g$, $a b b c d d$ dec ff.

Aunque el libro tercero del Arte poética trata de la poesía mélica, y de sus composiciones, se hace una breve incursión en el terreno de la poesía épica para hacer constar que en esta poesía existen tres clases de composición: los serventesios, los romances y las rimas sueltas.

El serventesio «es voz provenzal» y consiste en «un decir largo, como se requiere en el poema épico». Las partes de las que se componen reciben el nombre de cantos, según Dante, y capítulos, según Petrarca. Se hacen con cuartetos o tercetos, siendo estos últimos los más frecuentes, entrelazados de manera que «el siguiente terceto concierta con el anterior solamente en el segundo verso, de este modo: $a b a d b d »$. El último terceto de la serie se convierte en un cuarteto, «pues se añade un verso al final, a modo de vuelta, el cual concierta con el segundo del terceto de este modo: abab». Análogamente, si se trata de una serie de cuartetos, el cuarteto final se convierte en quinteto, pues se añade también un verso que concierta con «el último del cuarteto de esta manera: $a b b c c$ ».

Los romances (romanzi) se conciben en relación con el verbo romanzare, esto es, novelar, materia que corresponde al libro primero del Arte poética: «Pero de los romances se ha dicho bastante en el primer diálogo».

En cuanto a las rimas sueltas, «no sometidas a ninguna norma, a las cuales sometemos las canciones, los sonetos, las baladas, las frótolas, los madrigales, los serventesios y las estancias», se hace ver cómo «la poesía siempre se reservó y se reservará la libertad para componer». Mención expresa se hace de la octava real, u octava rima, «composición vaga y grave, a veces con imitación de actos dignos de la poesía épica», con versos dispuestos «de este modo: $a b a b a b c c$ ». 
Existen, así pues, tres rimas «de las cuales se responden por orden derecho el primero al primero, el segundo al segundo», y la última rima «queda integrada en un pareado concorde». De estas octavas rimas «se componen aquellas que por excelencia se llaman estancias», por su agradable armonía y por su adecuada extensión, que no es tan breve como el terceto o el cuarteto, ni larga con exceso.

Composición propiamente mélica es la frótola, usada por los modernos, que está hecha con versos de ocho sílabas. Su estilo es «bajo, pero agradable y agudo», y sirve muy bien para «bromear con proverbios y con dichos festivos». Es conocida también cono balada o barceleta. La frótola es, en verdad, semejante a la balada, «pues tiene represa, mudanza y vuelta». Existen varios modelos. Uno de ellos es el que marca la siguiente frótola de Lorenzo el Magnífico:

Donne belle io hô cercato

Lungo tempo del mio cuore:

Ringratiato sia tu Amore,

Ch'io l'ho pur al fin trovato.

Ell'è forse in questo Ballo,

Che'l mio cuor furato havia:

Hallo seco, e sempre havrallo,

Quanto sia la vita mia.

Ell'è sì benigna e pia,

Ch'ella havrâ sempre il mio cuore.

Ringratiato sia tu Amore;

Ch'io l'hô pur al fin trovato.

La primera estrofa constituye la represa, «de pareados concordes entre ellos oblicuamente»; la segunda estrofa es la mudanza, también de cuatro versos, o dos pareados, que ahora «conciertan por derecho». La tercera estrofa representa la vuelta. Remite ésta a la represa, pero de forma que su primer verso rima con el último de la mudanza, mientras que los tres siguientes tienen la misma rima que la represa. Los dos últimos versos de la vuelta son una exacta repetición de los dos últimos de la represa. 
Otro modelo, con vuelta de sólo dos versos, pero con repetición de la represa, es la siguiente frótola de Serafino:
Ah, ah, ah, chi non ridesse
D'una sì diforme vecchia;
Che per bella ogn'hor si specchia,
Pur com'altri le credesse.
O' tenace openione,
Quanti tu ne'nganni al mondo:
Contra te non val ragione:
Crudeltâ tu metti al fondo.
Solo à te pensier giocondo
Le menzogne son concesse.
Ah, ah, ah, chi non ridesse
D'una sì diforme vecchia;
Che per bella ogn'hor si specchia, Pur com'altri le credesse.

La represa consta aquí de dos pareados con rimas por oblicuo, esto es, abrazadas. Se trata, en otras palabras, de una redondilla. La mudanza está formada también por cuatro versos con rimas por derecho, cruzadas. Consiste, por lo tanto, en una cuarteta. La vuelta es de dos versos, de los cuales el primero rima con el último de la mudanza, y el segundo con el primero de la represa. Ésta se repite, seguidamente, en su integridad.

Finalmente, en el libro tercero de la Poética toscana se hace referencia a la elegía, «común de los griegos y de los latinos», y a la sátira, «propia de los latinos», pues «es cosa digna que una y otra poesía no falte en nuestra lengua». También se dedican algunas páginas a la poesía yámbica y a los epigramas.

La elegía es «imitación de un suceso completo, lamentable, que se hace en tercetos». Aunque al principio "consistía en un lamento funeral y en alabar al muerto», más tarde se aplicó también a «cosas más ligeras», como los amores, ya que «los amantes, siendo por naturaleza aptos y dispuestos 
para lamentarse, parece que hicieron suya esta poesía».

La sátira es «imitación de un suceso vicioso y censurable, con versos desnudos y puros». El lenguaje ha de ser «sencillo y limpio», pero también «agudo», para reprender el vicio y tratar de enmendar la vida, con una visión «más bien universal que particular». En esto se diferencia de la poesía yámbica, «que reprende vicios de los particulares». Ariosto demostró que «se puede escribir la materia satírica perfectamente en tercetos», aunque, según Minturno, «le van bien las rimas sueltas y desnudas de consonancia». Por su parte, la poesía yámbica se puede escribir con versos de once o siete sílabas, en pareados, tercetos o cuartetos, y también en quintetos y sextetos. En cualquier caso, «las rimas sueltas de consonancia estarían muy bien en esta composición».

En cuanto al epigrama, se trata de una pequeña composición «con la cual se describe brevemente y agudamente todo lo que es digno de no ser olvidado». La brevedad es fundamental en el epigrama, que puede llegar a constar incluso de un solo verso, o de un pareado «con un verso de once sílabas y otro de siete», o con la misma medida, enlazados o no por la rima.

En el libro cuarto ${ }^{11}$ se trata de las sentencias (sentenze) y las palabras (parole), a través del diálogo que tiene lugar entre Ferrante Carafa y Minturno. Se acude a la autoridad de Aristóteles que define la sentencia como «lo dicho, pero no todo, sino lo que se debe seguir como cosa excelente y buena, o evitar, como triste y mala».

Contiene este libro algunas observaciones de interés para la métrica, entre ellas las relativas a los diptongos. Unos «proceden de la lengua romana y de la griega», otros son propios de la lengua toscana. En ocasiones, dos vocales contiguas se pronuncian separadamente. Así, la palabra oime consta de tres sílabas (o-i-me):

Oime terra è fatto il suo bel viso

(o-i-me-te-rraè-fat-toil-suo-bel-vi-so)

11 Las citas están tomadas de las páginas 282, 290-291, 298-300, 321-345, 356362 y 451 del original $(726,741-743,757-761,803-851,873-885$ y 1063 de la traducción). 
Pero también se puede dar una «reunión de vocales, que en griego se llama synaíresis». De esta manera, mediante la sinéresis, oime constaría sólo de dos sílabas:

Oime'l bel viso, oime'l soave sguardo

(oi-me'l-vi-so-oi-me'l-soa-ves-guar-do)

Algunas vocales contiguas, como ai, ei noi, forman diptongo al principio o en medio del verso; pero, al final, se pronuncian separadamente, como en fai (fa-i), lei (le-i), noi (no-i). Por otra parte, en la lengua toscana, también es posible «pronunciar tres vocales juntas, lo que podría llamarse triptongo», como iuo en lacciuolo.

El encuentro entre vocales puede tener lugar entre la última vocal de una palabra y la primera vocal de la palabra siguiente, ante lo cual cede una de estas dos vocales, es decir, se produce la elisión de una vocal, aunque Minturno no hace uso de este término. Así, encontramos ch'ascoltate, en lugar de che ascoltate, o la've en lugar de là ove. Puede también ocurrir que las vocales «se fundan totalmente», aunque «una y otra se oigan», produciéndose así la sinalefa, término que tampoco utiliza Minturno. Es lo que ocurre en la expresión siete offesi, donde se une la $e$ final de siete con la $o$ inicial de offesi.

Por lo que respecta a la rima, «la consonancia se entiende no con la escritura, sino con el sonido». Por eso pecto rima con metto, y sancto con tanto. En ocasiones, se asimila la $i$ a la $e$, y la $u$ a la $o$. De ahí que los antiguos rimaran crede con vidi, y virtude con prode.

En cuanto a las palabras que se emplean en el verso, se hace constar que no son en realidad diferentes de las de la prosa, aunque los gramáticos mantienen lo contrario, diciendo que «tiene más licencia el poeta al versificar y al componer las voces», atendiendo más al sonido de las palabras que a las cosas «para dar placer a los oídos». Pero lo cierto es que las palabras que utiliza Boccaccio en la prosa son las mismas que emplea Petrarca en el verso. Carece de sentido el 
afirmar que en el verso abundan más las palabras del género masculino, como nuvolo o nuvileto, y en la prosa las del género femenino, como nuvola o nuvileta.

En cualquier caso, se debe hacer buen uso de las aliteraciones y de palabras sugerentes, «de modo que la misma voz diga lo que se quiere expresar». Entre los juegos aliterativos, se alude a la paronomasia, con voces que «tengan las mismas consonantes y no se cambie más que alguna vocal», como amore y amaro, o torre y terra. Las «concordancias de letras o de sílabas» son a veces casuales, «sin que nosotros las busquemos»; pero otras veces son «buscadas y encontradas» por el poeta «con mucho estudio». En los siguientes versos se imita, respectivamente, «el dulce temblor del aura» y «el gemido del ruiseñor»:

E fra le fronde fremer dolce l'aura.

Tutte le notti si lamenta e piagne.

Para que los versos estén bien compuestos, hay que tener también en cuenta el número de sílabas, porque si «las palabras de una sílaba son muchas juntas, el habla parece ir a saltos cortos y frecuentes». En efecto, «las partículas de una sílaba hacen el verso lentísimo», y «aumentan la velocidad las que tienen acento en la tercera silaba delante de la última», como bellíssimo, tímido, plácido, con las que los latinos hacían los versos anapésticos y dactílicos, y los toscanos los esdrújulos. La voz «más larga que puede caber en el verso en lengua toscana» es la de siete sílabas, como la palabra invisibilemente, utilizada por Petrarca:

\section{Che'nvisibilemente i'mi disfaccio}

En el verso, junto a las sílabas, hay que hacer consideración de los acentos, que son «un accidente de la voz, cuando se eleva o se baja, o se adapta al entorno». Pueden ser agudos, graves y oblicuos. Son agudos «cuando la voz se eleva», y graves «cuando se baja». El acento oblicuo, «que en latín se llama circunflejo», es aquel que «se adapta al entor- 
no», de manera que, «según sea, se eleve o se baje». De las sílabas agudas y graves, pasa Minturno a hablar de las largas y breves. La sílaba es «larga por naturaleza» en suôno, cuôre, dolôre, y también lo es cuando «está seguida de dos consonantes», como ocurre en las palabras verso, corso, morto.

Cuando en verso termina en palabra aguda, la última sílaba «vale dos». Por el contrario, si termina en palabra esdrújula, las dos últimas sílabas no valen «más que una». Además del acento final del verso, existen otros en distintas posiciones. Así, en el heptasílabo, puede ir el acento en la segunda sílaba, en la tercera o en la cuarta.

Leggiádra ricoverse.

Con l'angélico seno.

L'alma dubbiósa e vaga.

En el endecasílabo, el acento puede incidir sobre la sílaba cuarta, o la sexta, o cuarta y octava, o sexta y octava; o cuarta, sexta y octava:

Se la mia vîta da l'aspro tormento.

La notte che seguî l'horribil caso.

Rapido fiûme, che d'alpéstra vena.

Di pensier in pensiér, di mónte in monte.

Spirto gentîl, che quélle mémbra reggi.

Cuando el acento recae sobre la sílaba cuarta, el endecasílabo es «más grave y más parecido al sáfico». También ha de caer en la octava, o en la sexta, ya que «el que es menos cohesionado es el que tiene el acento solamente en la cuarta». La variedad de ritmos será, en todo caso, la base de la buena versificación.

Los versos se relacionan entre sí mediante las consonancias, que algunos consideran como «el alma» de los versos, hasta el punto de que si fuesen privados de ella «perderían la vida». Pero no es así, porque «la consonancia es una cualidad del verso que entre los griegos y los latinos se consideró vicio». Hace constar Minturno que, gracias a «la excelencia de los buenos ingenios», era posible oír en su tiempo «las rimas 
(rime) que se llaman sueltas o desnudas».

Con el término rime se hace referencia a los versos y a las composiciones en general, de ahí que se pueda hablar de rimas sueltas o desnudas, es decir, carentes de la «consonancia» que hoy conocemos propiamente con el nombre de rima. Porque «el alma del verso, que es la medida de las sílabas bajo cierto número sometida, lo es sin la cohesión y los ornamentos de la consonancia». Puntualiza Minturno que se debe entender «por versos los latinos, y por rimas las composiciones vulgares». Ocurre que «el número de voces concordantes, que entre los griegos se llamaban ritmos (rhythmi), fueron llamados corruptamente, primero por los bárbaros y después por los nuestros, rimas (rime)». Y «rimas también se llamaron los versos que se adornaron de tales consonancias». Éstas pueden darse entre versos contiguos, o separados por «algún pequeño intervalo»; y «son menos deleitosas las que se responden de más lejos».

Al final de la obra, se pone de manifiesto - por boca de Vespasiano, interlocutor del primer diálogo- cuánto le debe a Minturno el estudio de la poesía. Del mismo modo que las Musas latinas han llegado hasta los tiempos modernos, las Musas toscanas «no tienen una obra más provechosa ni más digna de ser leída» que L'arte poetica. Minturno habría sido «el primero en dar perfectamente y poéticamente instrumentos tanto a los toscanos como a los latinos», siguiendo «el camino que Aristóteles y Horacio nos mostraron», por donde transitaron «Homero, Virgilio, Petrarca y Dante, y todos los antiguos que fueron apreciables».

Como hemos tenido ocasión de ver, la Poética toscana de Antonio Sebastiano Minturno contiene un extenso repertorio de consideraciones sobre la versificación italiana, que constituye un no desdeñable tratado de métrica renacentista. Algunas de las composiciones estudiadas -el soneto, la octava real, la sextina- son formas canónicas que han perdurado hasta nuestros días. Otras, como la balada o el madrigal, tienen sólo un interés histórico. Habría también que destacar el papel que se le otorga al estudio del cómputo silábico y a la distribución acentual, si bien las sílabas tónicas, marcadas 
por el acento, se consideran como agudas o como largas; y las átonas, no marcadas, como graves o breves. Para el cómputo silábico, se tienen en cuenta, además de la unión vocálica de los llamados diptongos y triptongos, los fenómenos de la elisión, la sinalefa y la sinéresis.

Pero tal vez la aportación fundamental de la métrica de Minturno sea la consideración del verso italiano por excelencia, el endecasílabo, como «verso entero», esto es, como unidad rítmica fundamental del conjunto poemático y no como mero ensamblaje de unidades menores o pies métricos. Esta idea habría de ser fielmente recogida por los tratadistas españoles de la época. Así, Juan Díaz Rengifo nos habla en su Arte poética española (1592) del verso italiano entero y de su quebrado, que «se compone de siete syllabas»" ${ }^{12}$. Como es natural, Rengifo considera también como entero el verso tradicional castellano, el octosílabo, y cita como ejemplo las coplas de don Jorge Manrique, que «se componen de dos versos enteros, y luego un quebrado; luego otros dos enteros, y otro quebrado ${ }^{13}$. Del mismo modo, Francisco Cascales distingue los versos castellanos de los italianos: «Éstos, unos son enteros; otros, rotos» ${ }^{14}$. Pero también el verso específicamente castellano, el octosílabo, puede tener su quebrado, «que es la mitad de un entero» ${ }^{15}$, y aduce asimismo el ejemplo de las coplas de don Jorge Manrique.

La edición bilingüe de L'arte poetica (Arte poética), llevada a cabo por la profesora María del Carmen Bobes Naves, aparece con el texto italiano y el español enfrentados, en páginas pares e impares respectivamente, lo que facilita en todo momento la confrontación de la versión española con la obra original, que reproduce en facsímil la edición príncipe (G. Andrea Valvassori, Venecia, 1564). Su título completo es L'arte poetica del Sig. Antonio Minturno, nella quale si contengono i precetti Heroici, Tragici, Comici, Satyrici, e

${ }_{12}$ DÍAZ RENGIFO, Juan: Arte poética española. Salamanca: Miguel Serrano de Vargas, 1592, pág. 15.

13 Ibid., pág. 26.

14 CASCALES, Francisco: Tablas, cit., p. 114.

15 Ibid., pág. 123. 
d'ogni altra Poesia: con la dottrina de'sonetti, canzoni, et ogni sorte di Rime Thoscane, dove s'insegna il modo, che tenne il Petrarca nelle sue opere. Et si dichiara a'suoi luoghi tutto quel, che da Aristotele, Horatio, et altri auttori Greci, e Latini è stato scritto per ammaestramento di Poeti. Los ladillos o anotaciones marginales, que se deben a Valvassori, se traducen también y se colocan en el margen correspondiente del texto español.

Ante un trabajo de esta magnitud -se trata de una obra en dos volúmenes, con un total de 1072 páginas, en las que se incluyen el texto original, la traducción española y el estudio previo- no cabe más que encomiar tal esfuerzo y obtener el conveniente provecho de su lectura. No hay que olvidar que, como indica la profesora Bobes, editora y traductora de la Poética toscana, se trata de «uno de los textos que son testimonio de las ideas que sobre la literatura fueron aceptadas y defendidas en el Renacimiento italiano»». 